\title{
Analysis of Consumer Behavior in Regard to the Beef Meat in Kosovo
}

\author{
Njazi Bytyqi ${ }^{1,2^{*}}$, Arben Verçuni ${ }^{2}$, Mustafe Pllana ${ }^{1}$, Ardita Jahja ${ }^{1}$, Hysen Bytyqi ${ }^{1}$ \\ ${ }^{1}$ Faculty of Agriculture and Veterinary, University of Pristina, Pristina, Yugoslavia; ${ }^{2}$ Faculty of Economy and Agribusiness, Agri- \\ culture University of Tirana, Tirana, Albania. \\ Email: "njazi.bytyqi@uni-pr.edu
}

Received August 24 $4^{\text {th }}, 2012$; revised September $24^{\text {th }}$, 2012; accepted October $1^{\text {st }}, 2012$

\begin{abstract}
In this study, consumer's behavior in the Kosovo in respect to beef meat was studied using different socio-economic variables assessed by so-called evaluation criteria as: "very important", "important", "same”, and "less important”. The overall objective of the study was to analyze the consumer behavior in regard to beef meat in Kosovo and possibly identify effects of different variables on consumer decision upon purchase of beef meat. Beef meat was perceived differently at various types of purchasing places. Important socio-economic variables explaining individual respondent differences in consumer behaviors regarding purchase of beef meat involved in our study were: price, label, package, quality, trust, and origin of the product, gender of consumer, monthly family income, family member size, employment status of respondents, different regions in Kosovo. Perceived quality, price and trust of the beef meat product were significantly more important $(\mathrm{P}<0.05)$ than all other characteristics no matter of gender, family size, respondent region, monthly economic income or other issues. Supermarkets and retail story's are the preferred place for buying beef meat for all family size groups ranging from $46.10 \%-72.06 \%$, respectively. Conclusions derived from the analysis suggest that assessment of consumer's behavior through evaluation criteria can contribute to a better understanding of consumer behavior in respect of beef meat and will have positive impact and improve linkages between farmers, traders, processors and consumers as last part of this chain in Kosovo.
\end{abstract}

Keywords: Consumer Behavior; Beef Meat; Evaluation Criteria; Socioeconomic Variables

\section{Introduction}

In order to strengthen market information services and improves market access for consumers in Kosovo, the European Agency for Reconstruction (EAR) in collaboration with the Ministry of Agriculture, Forestry and Rural Development (MAFRD) implemented a consumer survey as a part of the Marketing Support Project (MSP). Although the low economic status of people in Kosovo, last period a specific attention has been given to the different consumer perception based on their needs and opportunities, gender, living status, etc in Kosovo by giving encourage to diversification and attributes for meat and meat products. Characterized by semi-continental climate condition, Kosovo is situated in South-East part of Europe with about 2 million inhabitants. Total surface is $10.887 \mathrm{~km}^{2}$, out of this about $53 \%$ is arable land. Currently, the rural families in Kosovo count about 7.4 members. The farm size is small and 55\% of farms are 1 $3 \mathrm{Ha}$. Meat production in Kosovo is based on cow, sheep and chicken, respectively [1]. This study introduces the

\footnotetext{
*Corresponding author.
}

meat and meat product consumption patterns in Kosovo, considering that last years some new trends of food consumption are evident [2]. Reasons for these trends might be multifactor such as increasing interest for food safety, health concerns, quality products, preference for new products, socio-economic changes, food products of different packaging units, food description, etc. The meat sector, after dairy is the most important sector contributing directly to family income for rural households in Kosovo. The main meat consumed is beef, followed by chicken. The consumption of meat per capita in Kosovo is considered to be about $41 \mathrm{~kg}$. Kosovo farms cover about $19 \%$ of total country meat demand, the balance being imported. The chicken meat, $96 \%$ is imported while for beef, $75 \%$. Due to lower feed costs and export subsidies the imported meat and processed meat is usually cheaper than the equivalent Kosovo product. The major sources of imported meat and processed meat are for beef, Brazil and Poland, and USA [1]. However, due to some meat food safety events last decades in the world market by many authors [3-5], have been pointed out that the meat industry including consumer perception has 
changed. In the consumer psychology and behavior disciplines, it is widely recognized that there exists a distinct filter or gap between the external (objective) and the internal (subjective) world of consumers [6]. It has been indicated that a label and package of can serve as an important factors on overall qualitative perception of the consumer in the evaluation process $[4,7,8]$. Furthermore, meat quality, labeling and packaging could be as a future strategy for attracting consumer confidence $[9,10]$. Consumers who experienced (bought) meat with a quality label reported a more favorable attitude towards and a better knowledge of labeled meat [11]. To enable the further uptake of quality assurance program and in particular to ensure buyers and consumers are properly informed regarding meat, the quality, trust, price, label, package and origin were central pillars of the study initiatives. The overall Objective of the study was to analyze the consumer behavior in regard to beef meat in Kosovo and possibly identify effects of different variables on consumer decision upon purchase this meat.

\section{Material and Method}

The main focus of this paper was to evaluate and study of consumer's behavior with regard to beef meat in Kosovo. The survey was carried out among 1215 respondents from different regions and socio-economic groups. The interviews were conducted in super-markets (311) Wholesale story's (78), Retail story's (471), ambulant traders (45), green market (53) farms gate (257). The study was conducted during period June to November 2011 carried out by trained interviewers. Number of respondent perception per attitude variables (price, label, origin of the product, package, quality and trust) are presented in Table 1. All consumers' baying beef meat was chosen randomly during period of survey.

The information from interview were collected and inserted directly in questionnaire which contains qualitative and quantitative questions. The questionnaire was comprised of information according to where consumers were buying meat and their perceptions towards supply with these products and attitudes.

To assess the overall impact the questionnaire was also comprised of different socio-economic variables as: 1) Sex of consumer (Female, Male); 2) Monthly income: Group I: up to $200 €$, group II: 201 - $300 €$, group III: 301 - $400 €$, group IV: over $400 €$; 3) Employment status: (Yes-Employed and No-Unemployed; 4) Family member size: Group I: 1- 5, group II: 6 - 10, group III: >10; 5) Regions: Prishtina, Prizreni, Gjilani and Peja; 6) Ranges of age: I: > 20 years old, II: 21 - 35 years old, III: 36 - 50 years old, IV: $<50$ years old. To respondent perception was qualified according to their attitudes classifying the variables to the definition as: "very important", "important", "same" and "less important". Perception of consumers about beef meat was assessed using different variables: price, label, package, trust, and origin of the product (imported or local). Due to lack of consumers experience for interviews, poor quality of interview in some cases, and uncompleted records were removed from final analysis.

Statistical analysis: To analyze the results Discovering Statistics Using SPSS, second edition, Sage Publication Ltd. [12] was used. An analysis of variances was performed to analyze the level of significances for effects of different variables on perception of consumer about beef meat. While contingency analyses were used to analyze indicator's perception of consumers about beef meat using classification criteria's ("very important", "important", "same" and "less important”).

\section{Results}

Figure 1, depicts that beef meat with local origin seems

Table 1. Number of respondents according to different variables and product attitudes.

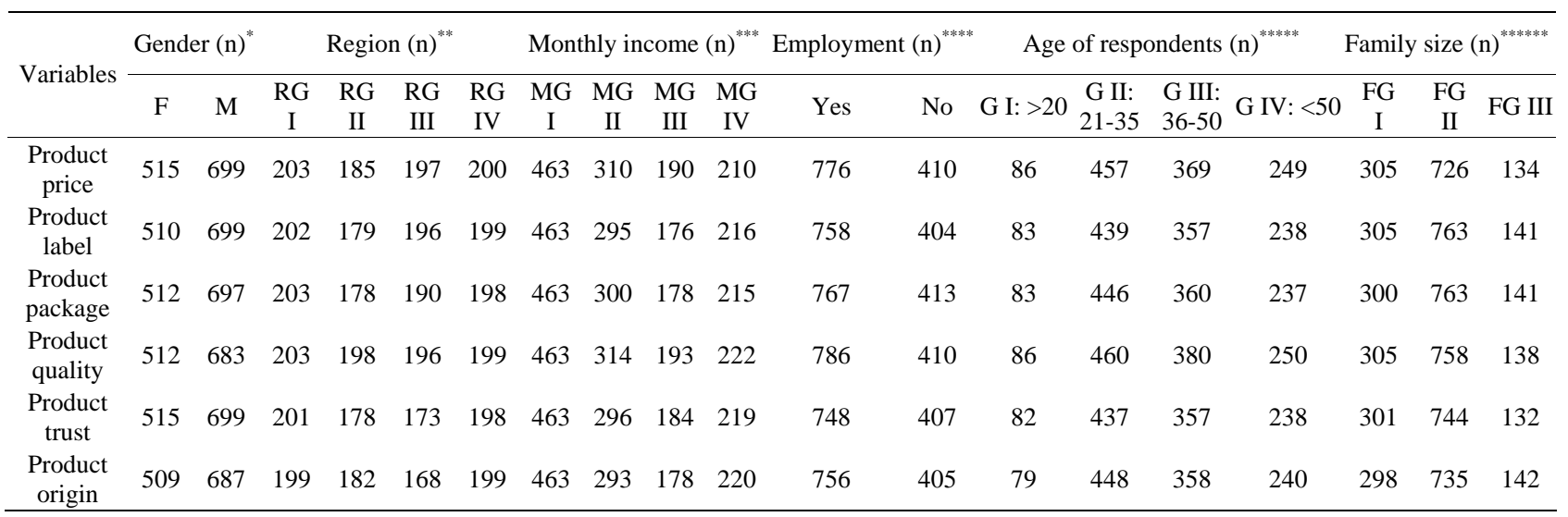

"F: Female, M: Male; ${ }^{* *}$ RG I: Prishtina, RG II: Prizreni, RG III: Gjilani, RG IV: Peja, ${ }^{* * *}$ Monthly income group MG I: <200 €, GR II: $201-300 €$, MG III: 301-400 €, MG IV: >400 €; ${ }^{* * * *}$ Yes-Employed, No-Jobless; ${ }^{* * * * *}$ Age of respondents: G I: > 20; G II: 21-35; G III: 36-50; G IV: <50; ${ }^{* * * * * *}$ Family size FG I: 1 - 5, FG II: 6 - 10, FG III: >10. 
to be more attractive for the Kosovar male consumer's (about 54\%), while females consider this less attractive (48.26\%). Both gender groups were noticed ranking consumption of local beef meat as "very important" (51.53\%) and "important" (27.78\%), comparing to them who do not see this attribute as important (5.60\%).

In regard to meat quality, results from this study show that both male and female consider this variable as "very important" at the level of $81.35 \%$, comparing to the consumers ranking this as "less important", only $0.41 \%$. Gender attitudes regarding beef meat price and product trust were ranking as "very important" at level 47.03 and 42.39\%, with small differences in perception when buyer is male or female. A significant of them ranked price and trust of beef meat as "important" (39.72 and 42.42\%). Only few consumers 5.91 and $4.21 \%$ give price and trust attitude as "less important”. Majority of female and male consumers rank beef meat label and package as "important”, female 46.51 and $46.31 \%$, while male 49.21 , $39.48 \%$, respectively. The given variable "same" belong about $7.30 \%$ for product price, 21.72 for label, 25.74 for packaging, 2.03 for quality, $10.85 \%$ for trust and 15.09 for origin of product, respectively. For both gender (male and female) their perception in regard to price $(\mathrm{P}<$ $0.0003)$, label $(\mathrm{P}<0.0010)$, package $(\mathrm{P}<0.0016)$, quality $(0.0025)$, trust $(0.0027)$, origin of product $(\mathrm{P}<$ 0.0036), respectively, were significantly different (Table 2).

Perception of consumers according to attitudes ranking "very important", "important", "same” and "not important" in regard to different regions in Kosovo are given in Figure 2. Variations between four regions involved in

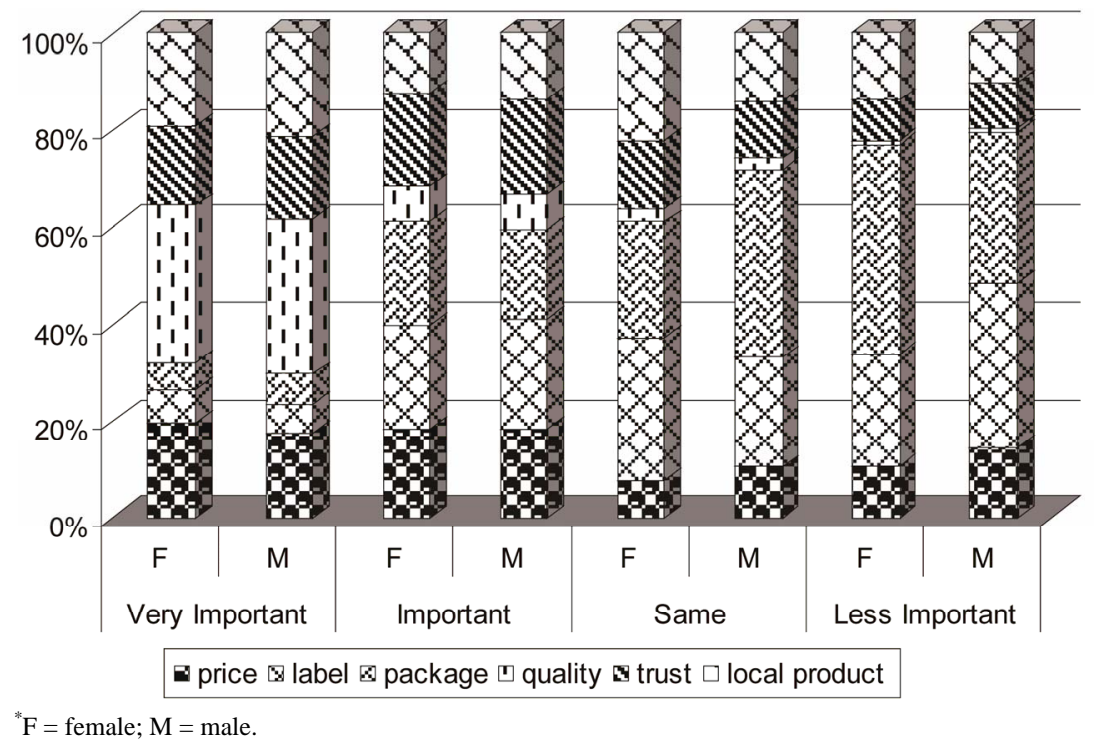

Figure 1. Gender share on consumers' behavior upon purchase of beef meat (\%).

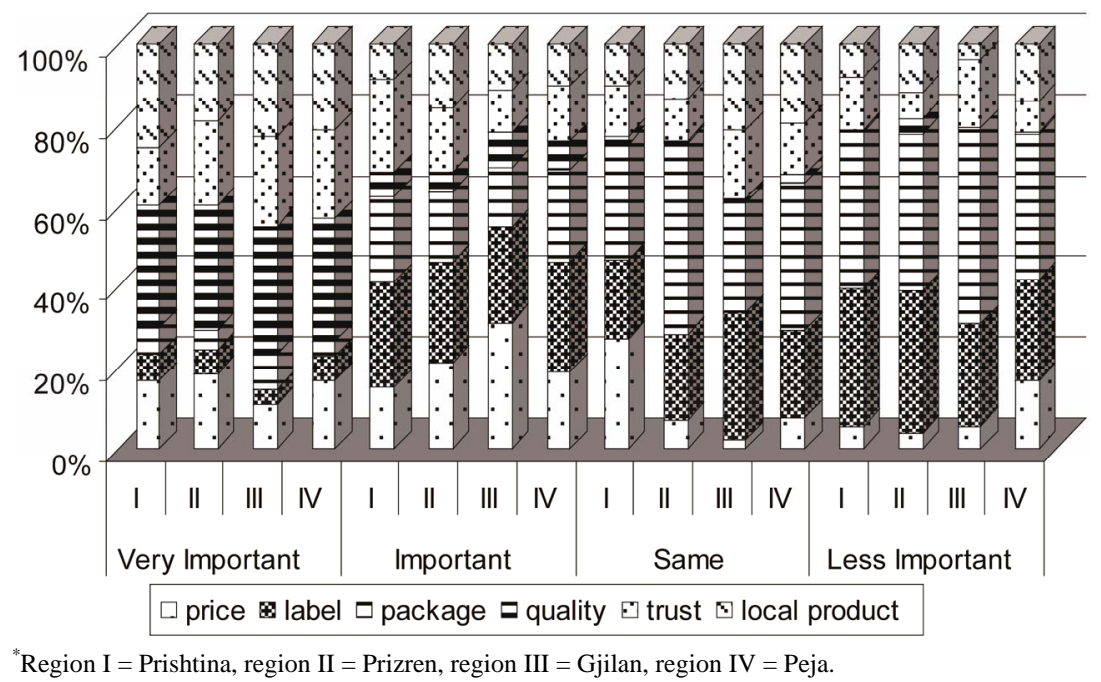

Figure 2. Region share on consumers' behavior upon purchase of beef meat (\%). 
this study were significant at level $(\mathrm{P}<0.05)$ for the beef meat origin, label and package, and with figurative differences but not significant $\mathrm{P}>0.05$ for price, quality and trust (Table 2).

Majority of respondents $(76.40 \%-95.12 \%)$ for product price, (97.31\% - 98.64\%) for product quality, (76.34\% - 89.21\%) for product trust and $(80.78 \%$ 87.68\%) rank as "very important" and "important" compare to them who considered as the "same" or "less important” (4.88\% - 23.60\%; 0.00\% - 2.70\%; 10.74\% 23.05\%; $12.34 \%$ - 15.46\%). Slightly different situation was with respondents with regard to product package and label. A significant number of them in almost all regions consider these variables as "less important", 18.72\% $24.29 \%$ and $13.30 \%$ - 18.66\%, respectively. Perception of consumers according to attitudes ranking "very important", "important”, "same” and "less important” in regard to monthly income per family in Kosovo are presented in Figure 3.

Variations between monthly income per family groups were significant for all variables (Table 2): Product price ( $\mathrm{P}<0.0270)$; product label $(\mathrm{P}<0.0184)$; product package $(\mathrm{P}<0.0150)$; product quality $(\mathrm{P}<0.0444)$; product quality $(\mathrm{P}<0.0238)$; product origin $(\mathrm{P}<0.0196)$, respectively. The results show also families with higher monthly income as family income group IV do not tend to pay attention to price $=35.40 \%$, label $=27.43 \%$, package $=22.57 \%$ and product origin $47.79 \%$, while they are more concerned mostly to quality $=89.38 \%$ and trust $=$ 59.52\%. Again, all respondents belonging to different monthly income groups consider all attitude variables as “very important” (42.43\%) and “important” (36.11\%), and much less of them consider as "same" (12.71\%) or "less important” (7.54\%). In regard to whether consumer

Table 2. Level of significances for effects of different variables on perception of consumer about beef meat (Prob $>$ F).

\begin{tabular}{|c|c|c|c|c|c|c|}
\hline Variables & Gender & Region & Monthly income & Employment & Age & Family size \\
\hline Product price & 0.0003 & 0.0619 & 0.0270 & 0.0035 & 0.0083 & 0.0029 \\
\hline Product label & 0.0010 & 0.0490 & 0.0184 & 0.0105 & 0.0083 & 0.0110 \\
\hline Product package & 0.0016 & 0.0400 & 0.0150 & 0.0088 & 0.0047 & 0.0045 \\
\hline Product quality & 0.0025 & 0.0512 & 0.0444 & 0.0086 & 0.0134 & 0.0089 \\
\hline Product trust & 0.0027 & 0.0606 & 0.0238 & 0.0042 & 0.0026 & 0.0036 \\
\hline Product origin & 0.0036 & 0.0484 & 0.0196 & 0.0042 & 0.0038 & 0.0067 \\
\hline
\end{tabular}

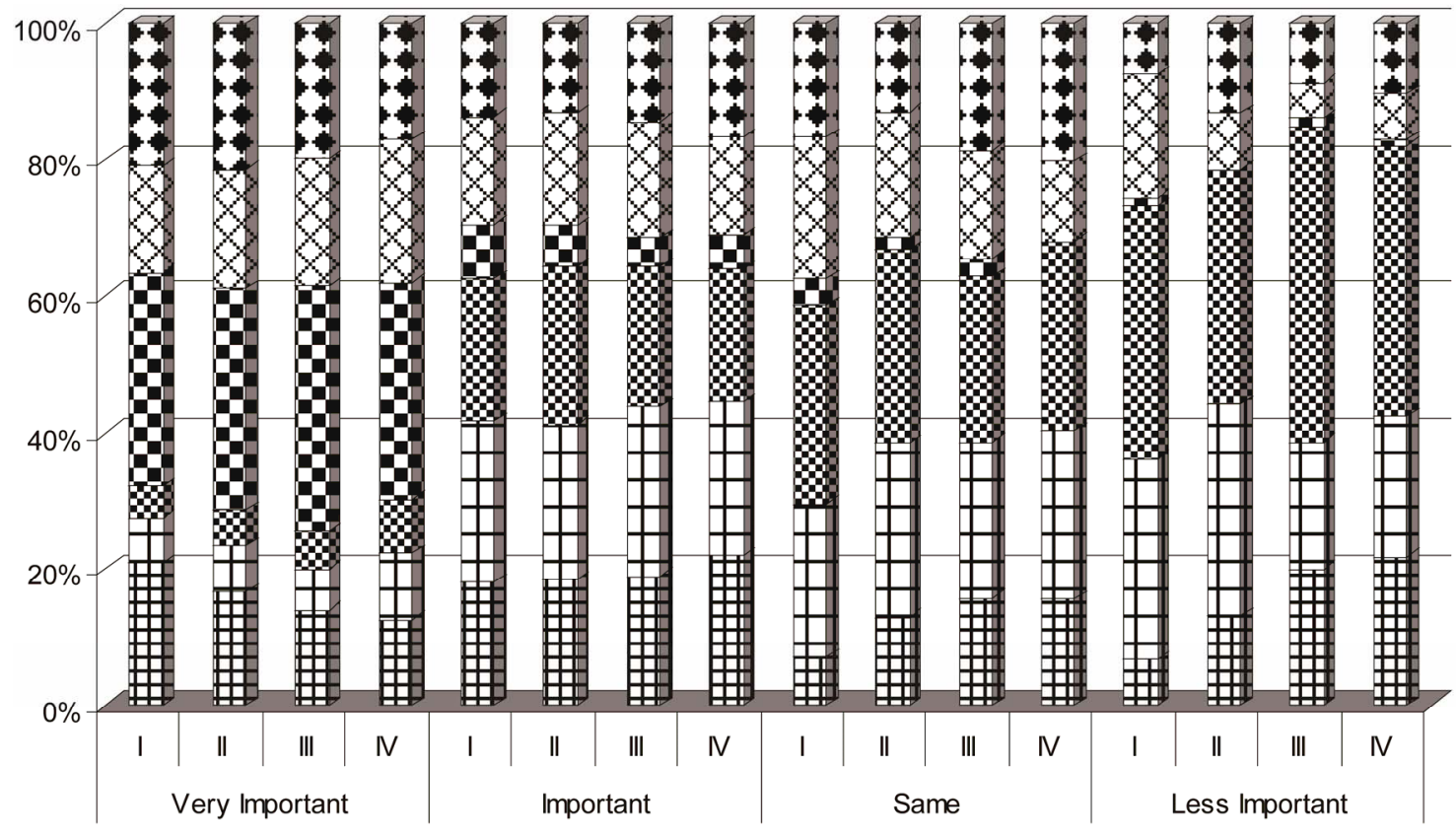

$\square$ price $\square$ label $\mathbf{Q}$ package $\square$ quality $\mathrm{B}$ trust $\square$ local product

*Monthly income: group I = up to $200 €$, group II = $201-300 €$, group III = $301-400 €$, group IV = over $400 €$.

Figure 3. Family monthly income share on consumers' behavior upon purchase of beef meat (\%). 
was employed or jobless, was received different perception (Figure 4).

Using the "same" attitude scaling all variables showed significant effects between these. Majority of respondents identified as employed consider product quality (85.9\%), trust (49.96\%), local product (59.16\%), and price (42.24\%) as "very important". Clearly, this rate was lower for unemployed respondents. However, high number of respondent for both group's consider product band $(8.45 \%-19.93 \%)$ and package $(16.65 \%-18.20 \%)$ as "less important".

Expanded families (Group IV) tend to pay more attention the price (56.22\%), trust (50.42\%) and Local product (79.20\%), compare to smaller families size (Figure 5).

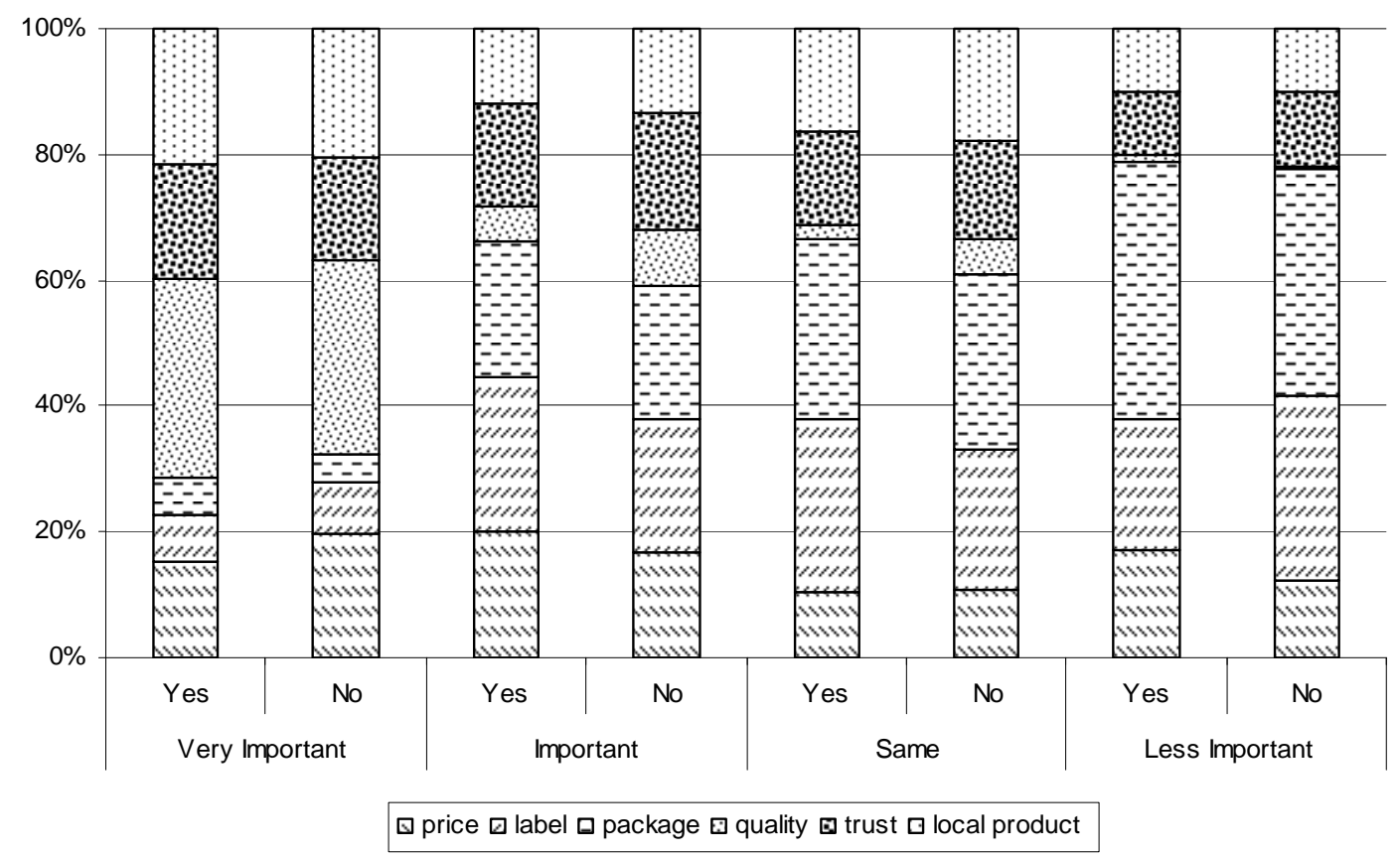

${ }^{*}$ Yes = Employed; No = Unemployed.

Figure 4. Employment status share on consumers' behavior upon purchase of beef meat (\%).

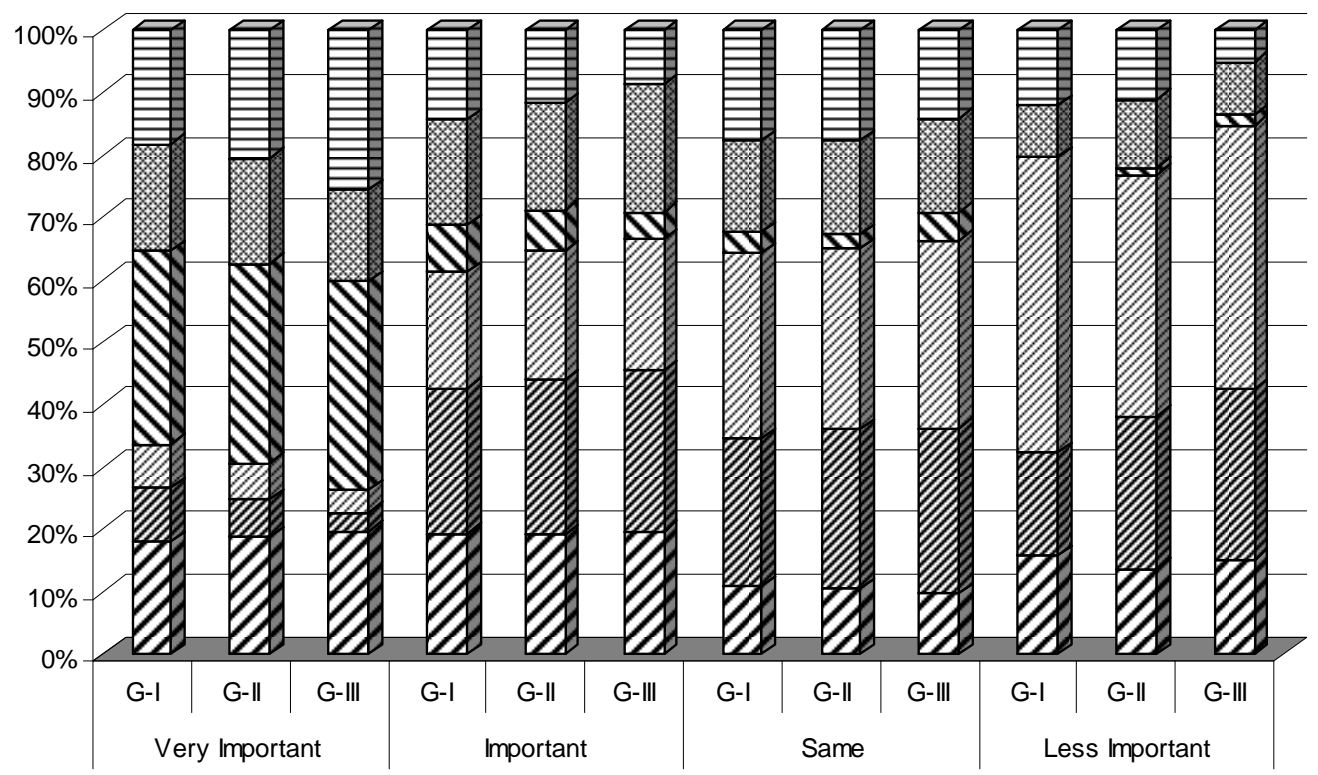

$\square$ price $\square$ label $\square$ package $\mathbf{\Delta}$ quality $\mathbf{0}$ trust $\boxminus$ local product

*Group I = Family member 1 - 5; Group II = Family member 6 - 10; Group III = Family member $>10$.

Figure 5. Family size share on consumers' behavior upon purchase of beef meat (\%). 
Family size and its possible effect on consumer's perception about beef in Kosova are presented on Figure 6.

Results gained show that most of the respondents perceive the quality of beef as product as a "very important" upon purchase this products, ranging from $(79.20 \%)$ to largest family members up to (85.79\%) for smaller size families. Again, about half of the respondents, used to consider label and package as a "same" factor ranging from $18.07 \%-19.61 \%$ and $21.08 \%-27.43 \%$ or "less important” ranging from $8.43-22.89$ and $17.04=$ $21.69 \%$, respectively, compared to quality, price and trust of beef products. Figure 7, depicts frequency where respondent are being furnished with meat and meat according to their family size products in Kosovo. Majority of respondents tend to furnish with beef at farm level (20.66\% - 25.53\%), through retail story's $(29.08 \%$ $40.66 \%)$, and in supermarket's $(17.02 \%-27.21 \%)$. Seems, that minimum number of families are purchasing these items in green markets $(0.01 \%-1.42 \%)$, from ambulant traders $(0.02 \%$ - $1.64 \%)$, wholesale story's $(6.16 \%$ 7.312\%).

Differences between groups (Table 2) were not significant $(\mathrm{P}>0.0780)$.

The results from Figure 8, indicates that there is e ten- dency showing employment respondents being furnished with beef on retail story's (66.24\%), wholesale story's (74.36\%) and supermarkets (67.52\%) compared to respondents indicated as jobless buying these items more at farm level (65.50\%) in green market (66.72\%) ), ambulant traders (57.14\%). Differences between two groups of respondents in this regard were highly significant $(\mathrm{P}<$ 0.0001).

\section{Discussion}

This research has confirmed the usefulness of the Kosovar consumers how they assess beef quality and place of purchase. Furthermore, the study has shown that due to some socio and economic variations there are some differences between consumers in Kosovo in relation to their attitudes for assessment of beef quality. Contrary to what the findings of [13] for European countries where country of origin and place of purchase are frequently included in the first rank for most consumers, Kosovar consumers mostly due to soci-economic reasons appear to rely predominantly on characteristics like price, quality and trust of beef meat product. However, there is slight tendency for favoring local beef meat produced

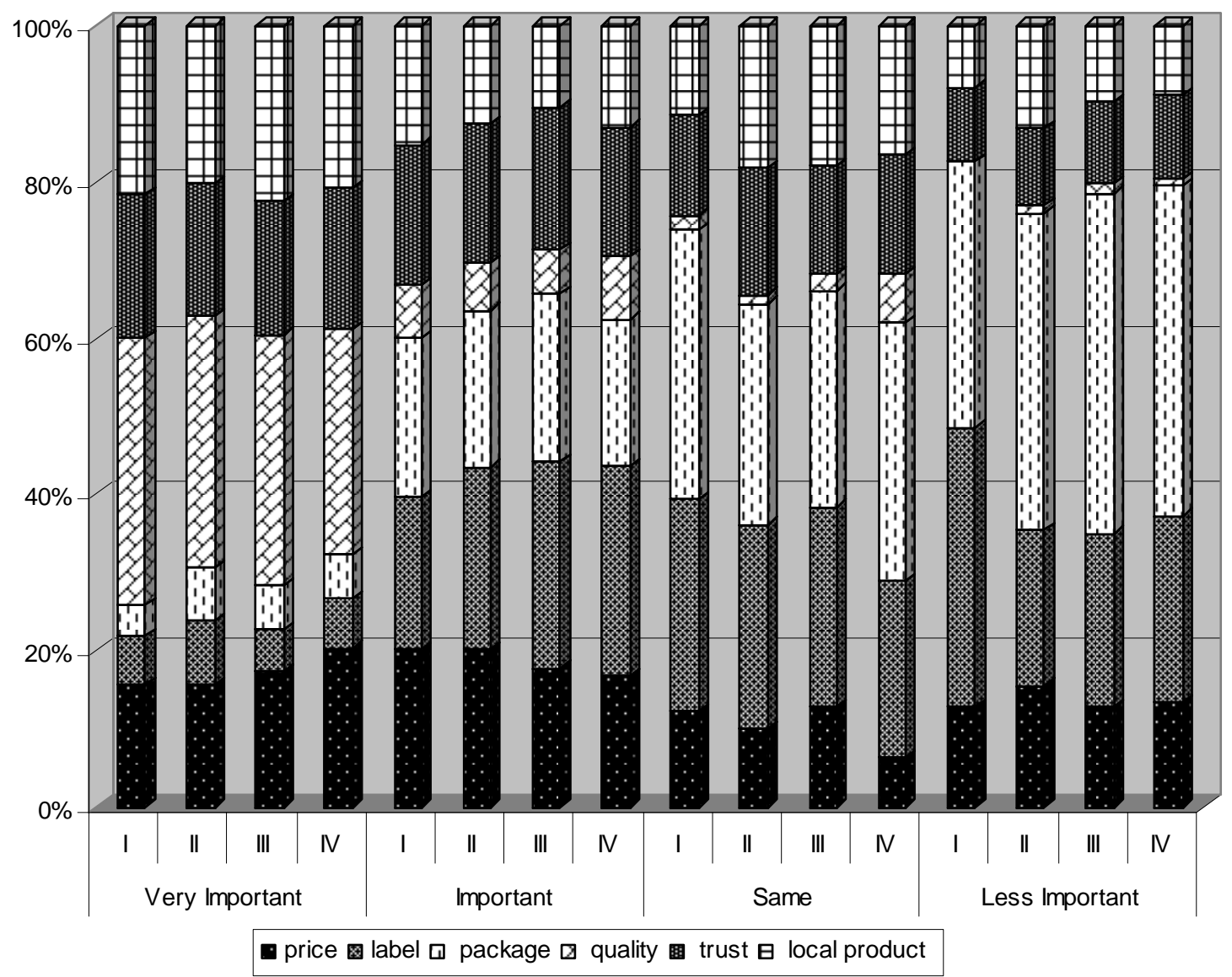

Figure 6. Impact of family size on consumers' behavior share upon purchase of beef meat (\%). 


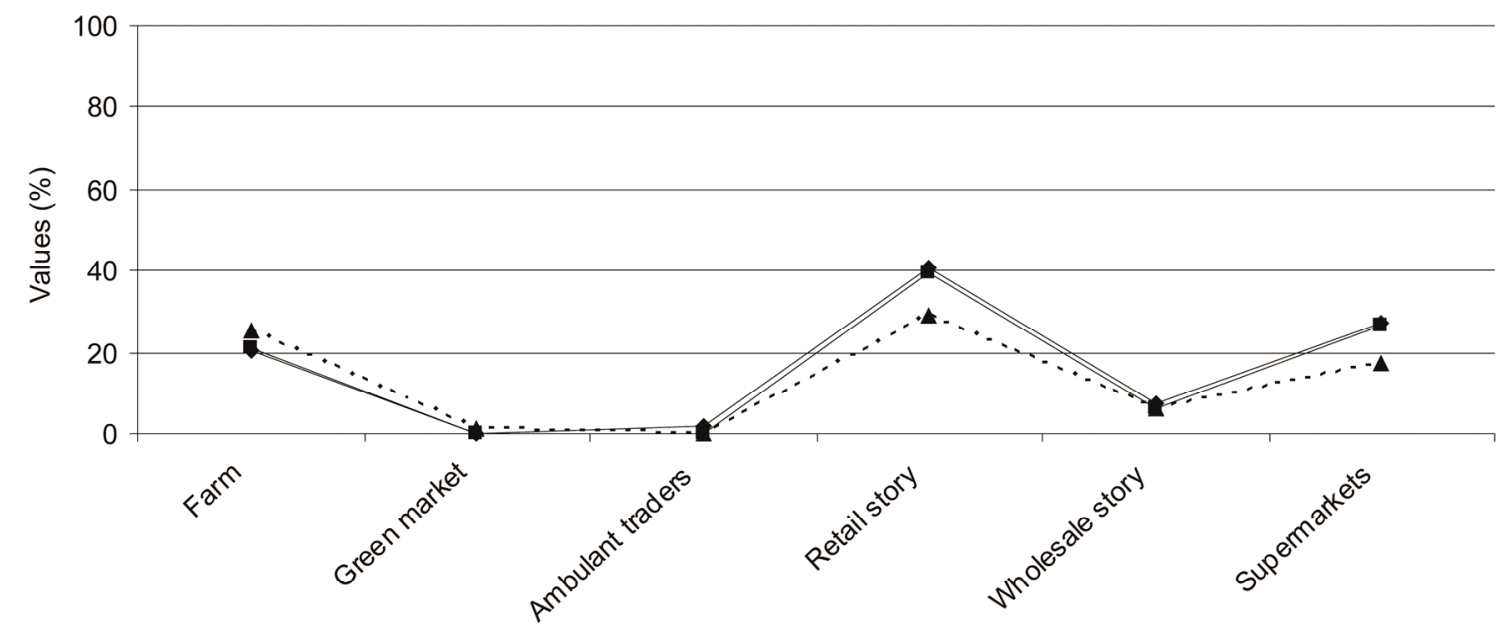

Purchese of meat products

*Group I = Family members 1 - 5; Group II = Family members 6 - 10; Group III = Family members > 10.

Figure 7. Frequency of respondents furnished with beef meat according to family size.

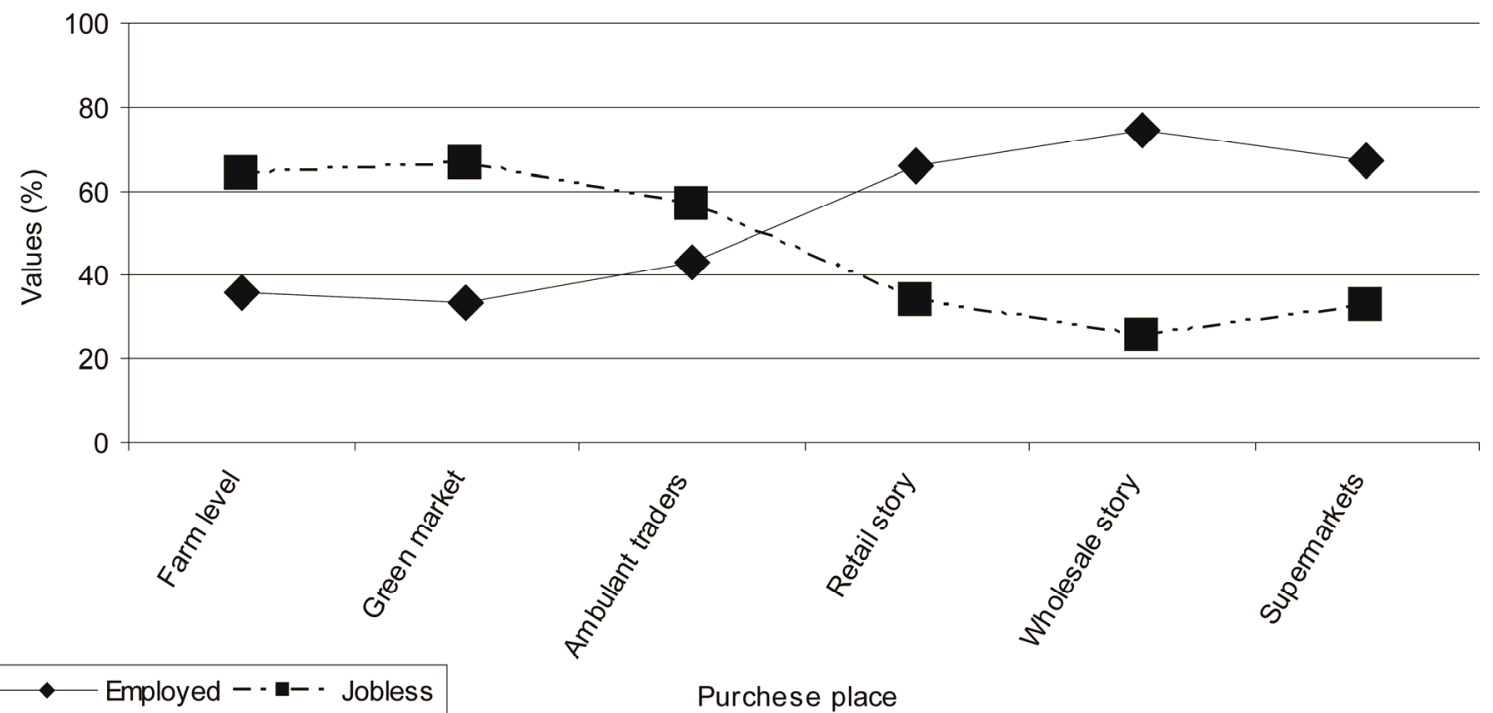

Figure 8. Frequency of respondent furnished with meat according to employment status.

locally and qualified as fresher meat in this respect. Supermarkets and retail story's are the preferred place for buying meat for all family size groups Group I $=69.87 \%$, Group II $=72.06 \%$ and Group III $=46.10 \%$, respectively. However, expanded size families (i.e. Group III) tend to purchase or use their own farm sources for meat consumption (about $45.53 \%$ ), which is partly due to the rural family tradition in Kosovo. Purchase of meat from ambulant traders and green market it seems to be much less preferred place for buying meat for all family size groups ranged from $0.13 \%-1.64 \%$. This is also due to quality hygiene and packaging of meat offered in those places by traders. Due to income and purchase capabilities, it is also evident that job less respondents are more prone to purchasing meat from illegal traders (i.e. green market, ambulant traders,) compare to those who are employed who are used mostly to purchase meat in su- permarkets, retail stories and wholesale story's. Percep- tion of consumers in regard to label, packaging and product origin it is not surprising that are considered of "same" or lesser important compare to price, quality and trust of the product. Given the importance of different variables and place where beef meet is being purchased, correct perceptions influencing the interpretation may impact on both initial purchase behavior, consumer sat- isfaction with the product and useful strategy for beef meat. Perceived quality beef product and trust were sig- nificantly more important than all other characteristics no matter of gender, family size, respondent region, monthly economic income or other issues. 


\section{Conclusion}

Study of their perception in regard to where meat and meat product is being exposed (wholesale, farm door, green market, retail markets, supermarkets) will have positive impact and improve linkages between farmers, traders, processors and consumers as last part of this chain. Given the importance of quality and trust to the Kosovar consumer as an indicator of beef marketing strategy, future study may be necessary to further explore the concept of quality and trust as perceived by consumers and to identify the factors which might have an effect in a consumer's mind before arriving at assessment of these indicators for a beef product at purchasing place. Due to the fact that this study on consumer's behavior on beef meat is a rather very narrow concept for Kosovo meat industry, in order to reach conclusions at broader aspect related to the respective industry, is necessary expansion of mythology to other species (i.e. sheep, goat, poultry, etc) and its products.

\section{REFERENCES}

[1] Agriculture and Rural Development Plane 2007-2013, “Chapter 1. The Rural Development Context of Kosovo," 2006, pp: 9-20. http://ampkosovo.com/ardp.html.

[2] H. Bytyqi, M. Vegara, M. Gjonbalaj, H, Mehmeti, H, Gjergjizi, I. Miftari and N. Bytyqi, "Analysis of Consumer Behavior in Regard to Dairy Products in Kosovo," Journal of Agricultural Research, Vol. 46, No. 3, 2008, pp. 281-290.

[3] E. T. Becker, E. Benner and K. Glitsch, "Consumer Perception of Fresh Meat Quality in Germany,” British Food Journal, Vol. 102, No. 3, 2000, pp. 246-266. doi:10.1108/00070700010324763

[4] S. Issanchou, "Consumer Expectations and Perceptions of Meat and Meat Product Quality,” Meat Science, Vol. 43,
Suppl. 1, 1966, pp. S5-S19.

[5] N. Richardson, H. MacFie and R. Shepherd, "Consumer Attitudes to Meat Eating,” Meat Science, Vol. 36, No. 1-2, 1994, pp. 57-65. doi:10.1016/0309-1740(94)90033-7

[6] E. Risvik, “The Food and I: Sensory Perception as Revealed by Multivariate Methods, In: L. Frewer, E. Risvik, and H. Schifferstein, Eds., Food, People and Society: A European Perspective of Consumers' Food Choices, Springer-Verlag, Heidelberg, 2001, pp. 23-37.

[7] G. K. Grunert, L, Bredahl and K. Brunsø, "Consumer Perception of Meat Quality and Implications for Product Development in the Meat Sector-A Review," Meat Science, Vol. 66, No. 2, 2004, pp. 259-272. doi:10.1016/S0309-1740(03)00130-X

[8] J. Caswell, "Current Information Levels on Food Labels," American Journal of Agricultural Economics, Vol. 74, No. 5, 1992, pp. 1196-1201. doi:10.2307/1242785

[9] B. E. Peterson, E. Van Eenoo, A. McGuirk and V. P. Preckel, "Perceptions of Fat Content in Meat Products," Agribusiness, Vol. 17, No. 4, 2001, pp. 437-453. doi:10.1002/agr.1028

[10] A. M. Wit, P. M, Koopmans and M. L. Kortbeek, "Consumer-Oriented New Product Development: Principles and Practice,” In: M. Meulenberg, Ed., Innovation of Food Production Systems: Product Quality and Consumer Acceptance, Wageningen Pers, Wageningen, 1998, pp. 37-66.

[11] W. Verbeke and J. Viaene, "Consumer Attitude to Beef Quality Labeling and Associations with Beef Quality Labels,” Journal of International Food and Agribusiness Marketing, Vol. 10 No. 3, 1999, pp. 45-65. doi:10.1300/J047v10n03_03

[12] A. Field, "Discovering Statistics Using SPSS,” 2nd Edition, Sage Publication Ltd., London, 2006.

[13] K. Glitsch, "Consumer Perceptions of Fresh Meat Quality: Cross National Comparison,” British Food Journal, Vol. 102, No. 3, 2000, pp. 177-194. doi: $10.1108 / 00070700010332278$ 